\title{
Dependent and independent causes of hypercalcemia
}

\author{
Rahmathulla Safiyul Rahman ${ }^{1 *}$, Hussain Fuad Al-Saffar ${ }^{2}$, Omar Abdu Alasiri $^{3}$, \\ Nada Jameel Alata ${ }^{4}$, Abdulaziz Abdulmajeed Almalki ${ }^{5}$, Mohammad A. J. Althenayan ${ }^{6}$, \\ Mohammad Mulaihan Althubaity ${ }^{7}$, Saleh Ibrahim AlGhammas ${ }^{8}$, Lojain Suweelim Alsubhi', \\ Baqer Mohammedsaeed Alwaheed ${ }^{2}$, Farah Abdulkareem Almomen ${ }^{10}$
}

\author{
${ }^{1}$ Department of Internal Medicine, Sameera Medical Center, Jeddah, Saudi Arabia \\ ${ }^{2}$ College of Medicine, Imam Abdulrahman Bin Faisal University, Dammam, Saudi Arabia \\ ${ }^{3}$ Department of Emergency Medicine, Dhurma General Hospital, Riyadh, Saudi Arabia \\ ${ }^{4}$ Department of Internal Medicine, King Fahad General Hospital, Jeddah, Saudi Arabia \\ ${ }^{5}$ Department of Internal Medicine, Al Iman General Hospital, Riyadh, Saudi Arabia \\ ${ }^{6}$ Department of Internal Medicine, Adan Hospital, Hadiya, Kuwait \\ ${ }^{7}$ College of Medicine, University of Debrecen, Debrecen, Hungary \\ ${ }^{8}$ Al-Khazan Primary Healthcare Center, Ministry of Health, Qassim, Saudi Arabia \\ ${ }^{9}$ College of Medicine, King Abdulaziz University, Jeddah, Saudi Arabia \\ ${ }^{10}$ College of Medicine, Imam Mohammad Ibn Saud Islamic University, Riyadh, Saudi Arabia
}

Received: 19 December 2021

Accepted: 03 January 2022

\section{*Correspondence: \\ Dr. Rahmathulla Safiyul Rahman, \\ E-mail: safiyul@gmail.com}

Copyright: () the author(s), publisher and licensee Medip Academy. This is an open-access article distributed under the terms of the Creative Commons Attribution Non-Commercial License, which permits unrestricted non-commercial use, distribution, and reproduction in any medium, provided the original work is properly cited.

\begin{abstract}
Previous clinical studies show that the condition is significantly associated with mortality and increased cardiovascular morbidities. Accordingly, it is essential to conduct adequate diagnosis and evaluation to assess these cases properly. Studies show that different etiologies have been associated with hypercalcemia development with variable prevalence rates among different populations. Reduced PTH levels among patients with hypercalcemia indicate the presence of a non-PTH-dependant etiology for hypercalcemia. We have discussed various causes of hypercalcemia, including dependant and non-dependant causes. We found that malignancy-induced hypercalcemia is the commonest non-PTH-dependant etiology of hypercalcemia. Many malignancies were reported in the literature to attribute to the development of hypercalcemia. Vitamin D-mediated hypercalcemia was also reported as another common etiology for the condition. It might occur secondary to overdosing, immobilization, endocrine disorders, and granulomatous diseases. Other familial and congenital causes were also reported in the literature and discussed.
\end{abstract}

Keywords: Hypercalcemia, Etiology, Parathyroid, Parathormone, Vitamin D, Calcium

\section{INTRODUCTION}

Calcium metabolism is regulated by the actions of vitamin $\mathrm{D}\left(1,25(\mathrm{OH})_{2}\right.$ Vit $\left.\mathrm{D}\right)$ and parathormone $(\mathrm{PTH})$ on the bone, gut, and kidneys (Figure 1). Due to different factors and etiologies, high calcium levels (hypercalcemia) have been reported to be common among the different age groups. Moreover, previous clinical studies show that the condition is significantly associated with mortality and increased cardiovascular morbidities. Therefore, it is critical to identify patients with hypercalcemia to adequately treat them and apply better interventions to decrease the burden of the disease. ${ }^{1}$

Before establishing the diagnosis, it is essential to identify the underlying etiology. Studies show that different etiologies have been associated with hypercalcemia development with variable prevalence rates among 
different populations. ${ }^{2}$ However, it has been shown that primary hyperparathyroidism is the commonest cause among various population groups. On the other hand, malignancy was the commonest cause among other settings, and primary hyperparathyroidism is the second commonest cause. This indicates wide variations in the incidence of causes of hypercalcemia, which clinicians should consider when evaluating these patients. ${ }^{3}$ The present study aims to elaborate on the different dependant and non-dependant causes of hypercalcemia based on evidence from relevant studies.

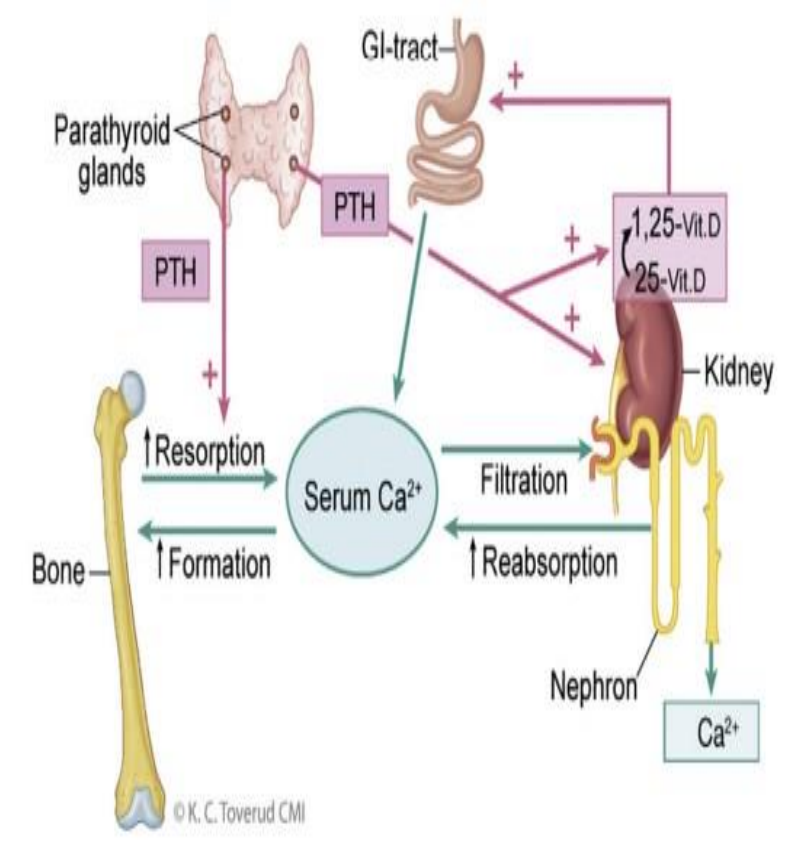

Figure 1: Parathormone-mediated calcium homeostasis. ${ }^{1}$

\section{LITERATURE REVIEW}

This literature review is based on an extensive literature search in Medline, Cochrane, and EMBASE databases which was performed on $27^{\text {th }}$ November 2021 using the medical subject headings (MeSH) or a combination of all possible related terms, according to the database. To avoid missing potential studies, a further manual search for papers was done through Google Scholar while the reference lists of the initially included papers. Papers discussing dependent and independent causes of hypercalcemia were screened for useful information. No limitations were posed on date, language, age of participants, or publication type.

\section{DISCUSSION}

\section{PTH-dependant hypercalcemia}

Hypercalcemia that occurs secondary to PTH-dependent causes is most commonly attributed to parathyroid tumors, leading to primary or tertiary hyperparathyroidism development. Thus, primary hyperparathyroidism might occur as a single disorder and be part of another syndrome. On the other hand, evidence shows that chronic renal failure is usually associated with tertiary hyperparathyroidism. Therefore, adequate evaluation should be conducted before establishing the diagnosis of the presenting children to enhance the line of treatment and related outcomes. In addition, gestational maternal hypocalcemia was previously associated with PTH-dependant hypercalcemia in children, but as nonparathyroid tumor-related etiology. ${ }^{4}$

It has been indicated that hyperparathyroidism occurs in all types of multiple endocrine neoplasias (MEN). In this context, it has been shown that most patients presenting with these conditions usually suffer from hypercalcemia as their first presentation. ${ }^{5-7}$ It has been furtherly shown that hypercalcemia might also be associated with patients suffering from hyperparathyroid jaw-tumor syndrome. ${ }^{7}$ These syndromes are attributed to different genetic mutations. Therefore, it has been recommended that biochemical surveillance to detect abnormal parathyroid levels is essential to intervene against the development of these disorders. In addition, PTH-dependant hypercalcemia might also occur as a non-syndromic event. For instance, studies indicate that familial hypocalciuric hypercalcemia is a direct cause for developing hypercalcemia. However, these studies suggested that hypercalcemia is more probably attributed to impaired renal functions and not due to parathormone levels. ${ }^{8}$ Familial isolated hyperparathyroidism was also reported in the literature as a potential cause for hypercalcemia related to PTH levels. It has been shown that patients suffering from this condition usually develop primary hyperparathyroidism irrespective of other tumors that might alter PTH levels. It has been shown that the development of hypercalcemia in these patients usually occurs within ten years after the pathology of the condition has been documented. ${ }^{9}$ Evidence shows that neonatal severe primary hyperparathyroidism might also cause similar events in the same context. Evidence indicates that the condition might be lethal if left untreated within three months. Many pathological events were reported in the affected patients, including bone demineralization, respiratory distress, hypotonia, and hypercalcemia. ${ }^{10,11}$

In addition to the PTH-dependant causes, various investigations in the literature have assessed the impact of different causes that can affect calcium levels leading to hypercalcemia, which will be discussed in the current section.

\section{Vitamin-D-related causes}

Accidental overdosing and incorrect prescriptions of vitamin $\mathrm{D}$ can significantly lead to hypercalcemia secondary to vitamin $\mathrm{D}$ intoxication. ${ }^{12-15}$ It has been further demonstrated that high doses of vitamin D might also be complicated with hypercalcemia when used in 
therapeutic doses to treat patients with cystic fibrosis and rickets. ${ }^{16-19}$ Unfortunately, the mechanism and pathophysiology of the correlation between vitamin D levels and hypercalcemia has not been properly reported among the relevant studies. However, it has been previously shown that hypercalcemia is most probably not attributed to the actions of $1,25(\mathrm{OH})_{2} \mathrm{D}_{3}$. In this context, many studies have assessed the association between hypercalcemia and increased serum levels of $1,25(\mathrm{OH})_{2} \mathrm{D}_{3}$ in the affected patients. Furthermore, it has been demonstrated that increased levels of $1,25(\mathrm{OH})_{2} \mathrm{D}_{3}$ might occur secondary to different conditions, including reduced renal excretion and catabolism of the active compound $\left(1,24,25(\mathrm{OH})_{2} \mathrm{D}_{3}\right)$, phosphate depletioninduced increased synthesis of $1,25(\mathrm{OH})_{2} \mathrm{D}_{3}$ and overproduction of $1,25(\mathrm{OH})_{2} \mathrm{D}_{3}$ secondary to excess activation of the $1 \alpha$-hydroxylase enzyme..$^{2,20-22}$

It has been demonstrated that children suffering from idiopathic infantile hypercalcemia usually suffer from nephrocalcinosis, hypercalciuria, and hypercalcemia secondary to excessive production of $1,25(\mathrm{OH})_{2} \mathrm{D}_{3}$ concerning phosphate depletion and impaired activities of the $1 \alpha$-hydroxylase enzyme. In this context, evidence shows that the condition is not usually permanent as most cases resolve by one year. However, the condition lasted into adulthood. ${ }^{2}$ In addition, many granulomas and malignant diseases were also associated with increased synthesis and production of $1,25(\mathrm{OH})_{2} \mathrm{D}_{3}$-induced hypercalcemia regardless of renal actions. Previous relevant studies showed that hypercalcemia and increased $1 \alpha$-hydroxylase activities had been associated with increased production of $1,25(\mathrm{OH})_{2} \mathrm{D}_{3}$ in association with different conditions, including Hodgkin's, non-Hodgkin's lymphomas, and ovarian dysgerminomas. ${ }^{23,24}$ Hypercalcemia might also result from dysregulated production of $1,25(\mathrm{OH})_{2} \mathrm{D}_{3}$ in many granulomatous conditions, including human immunodeficiency virus (HIV) immune reconstitution syndrome, tuberculosis, sarcoidosis, subcutaneous fat necrosis of the newborn, histoplasmosis, cytomegalovirus infection, Crohn's disease, cat scratch fever, fungal granuloma including coccidioidomycosis, and leprosy. In addition, evidence shows that hypercalcemia among patients suffering from subcutaneous fat necrosis of the newborn can be lifethreatening. $1,3,4$

\section{Malignancy}

In addition to vitamin D-related hypercalcemia, it has been shown that many other conditions can lead to hypercalcemia, irrespective of vitamin D levels. For example, various previous studies demonstrated that hypercalcemia might be associated with many malignancies and related disorders, including dysgerminomas, hepatic tumors (including hepatocellular carcinoma and hepatoblastoma), neurological tumors (including neuroblastoma), rhabdomyosarcoma, and hematological malignancies (including myeloma, lymphomas, and leukemias).,25-28 However, it has been estimated that the incidence of these conditions in children might be less than $1 \% .^{29}$ These patients' increased calcium levels might occur secondary to osteoclastic bone resorption and osteolysis secondary to leukemias and metastasis. The evidence further shows that hormones (including parathyroid hormone-related protein, or PTHrP) are responsible for developing these events in the affected patients. Various studies demonstrated some tumors (including renal dysplasia, multicystic dysplastic kidney disease, renal cell carcinomas, benign congenital mesoblastic nephroma, pheochromocytoma, ovarian and breast carcinomas, dysgerminomas, and squamous cell carcinomas) are associated with the systemic release of PTHrP. This has been cumulatively associated with hypercalcemia in the affected patients. , $^{3,40-33}$

\section{Immobilization}

Hypercalcemia might develop secondary to prolonged immobilization following serious injuries. For instance, it has been estimated that $10-23 \%$ of children suffering from spinal cord injuries developed hypercalcemia. This has been preceded by hypercalciuria and is due to the suppression of the parathormone hormone. Another study also reported that single-limb fractures were also associated with the development of immobilization hypercalcemia. $^{34}$ Maynard et al concluded that adolescents and males tend to have an increased risk of developing immobilization hypercalcemia, most probably due to the high bone mass and rapid growth. ${ }^{35}$ However, it should be noted that this pathology is poorly understood and needs further elaboration, and is most probably attributed to bone metabolism and associated activities.

\section{Renal tubular disorders}

Evidence shows that hypercalcemia has been reported among patients with distal renal tubular acidosis. ${ }^{36}$ Among other manifestations, hypercalcemia was also reported among patients with Bartter syndrome type 1..$^{37,38}$ However, it has been shown that the incidental hypercalcemia in these patients is attributed to a malignant increase in circulating parathormone levels. ${ }^{39}$

\section{Vitamin A and drugs toxicities}

The development of milk-alkali syndrome is secondary to the administration of inappropriate sodium and calcium bicarbonates in patients with impaired renal functions, prolonged administration of toxic doses of vitamin A and its derivatives, and thiazides have been associated with hypercalcemia. In addition, influencing the activities of osteoclastic-related bone resorption has been associated with administering Isotretinoin (13-cis-retinoic acid). However, it should be noted that the toxicity of vitamin A is a rare manifestation that is not commonly reported. It has also shown that hypercalcemia secondary to administration of thiazides usually results from increased reabsorption of calcium at the renal tubules. ${ }^{4,40-42}$ 


\section{Endocrine disorders}

Studies also reported that hypercalcemia could significantly develop secondary to various endocrine disorders, including severe congenital hypothyroidism, thyrotoxicosis, Addison's disease, and pheochromocytoma. Thus, PHTrP might be the leading cause of hypercalcemia in patients with pheochromocytoma. ${ }^{31,33,43}$ On the other hand, increased intestinal calcium absorption might be the etiology of hypercalcemia in patients with Addison's disease. ${ }^{44}$ This has been furtherly reported to be associated with an impairment in the levels of mineralocorticoid hormone. On the other hand, there is a significant impairment in the metabolism of many materials, including bone metabolism, among patients with thyrotoxicosis, resulting in hypercalcemia secondary to bone resorption..$^{45}$ In addition, many of them reported hypercalcemia in children with severe congenital hypothyroidism. However, the mechanism is not adequately comprehended, and the condition is usually asymptomatic in many affected children. In the same context, it has been shown that hypercalcemia might result from the administration of levothyroxine in these children, secondary to increasing $1,25(\mathrm{OH})_{2} \mathrm{D}_{3}$ levels. ${ }^{46,47}$

\section{Congenital diseases and inborn errors of metabolism}

Hypercalcemia was also reported among children with different congenital diseases. For instance, it was reported that despite the normal levels of PTH, hypercalcemia and hypercalciuria were significantly associated with children suffering from Jansen's metaphyseal chondrodysplasia. Patients with down syndrome were also reported to suffer from nephrocalcinosis and hypercalcemia. However, these disorders are not very common with the syndrome. The pathophysiology of hypercalcemia in these patients is not adequately understood. However, some evidence indicates that it might be secondary to the increased calcium absorption as affected patients do not respond to the oral administration of calcium supplementation. In another context, studies show that 5-50\% of children with Williams syndrome usually have hypercalcemia. It might develop as an autosomal-dominant disorder or might be sporadic. It should be noted that the condition usually subsides within weeks after the manifestations start. However, the exact mechanism of these events is not adequately reported. ${ }^{48-50}$

Nutritional disorders might also lead to the development of hypercalcemia in children. For instance, it has been shown that phosphate depletion and enriched calcium formulas are associated with hypercalcemia in children. Therefore, amelioration of the calcium/phosphate content in the diets of newly born infants is essential to avoid the development of hypercalcemia and associated complications in this population group. Other inborn disorders might include blue diaper syndrome, disaccharide intolerance, congenital lactase deficiency, and hypophosphatasia. Evidence shows that the latter condition is usually associated with impaired bone mineralization and around $30 \%$ of children usually develop hypercalcemia. It has been furtherly shown that the condition might also manifest with immobilized adults. In addition, nephrocalcinosis and hypercalcemia were also reported among patients with congenital lactase deficiency secondary to severe diarrhea and weight loss. Furthermore, it has been shown that nephrocalcinosis usually persists even after initiating a lactose-free diet. However, it has been shown that hypercalcemia usually subsides within weeks. A similar mechanism and events were also reported for patients suffering from a sucroseisomaltase deficiency. Therefore, urgent efforts are needed to identify these children and adequately treat them. ${ }^{3,4}$

\section{CONCLUSION}

Reduced PTH levels among patients with hypercalcemia indicate the presence of a non-PTH-dependant etiology for hypercalcemia. Accordingly, it is essential to conduct adequate diagnosis and evaluation to assess these cases properly. We have discussed various causes of hypercalcemia, including dependant and non-dependant causes. We found that malignancy-induced hypercalcemia is the commonest non-PTH-dependant etiology of hypercalcemia. Many malignancies were reported in the literature to attribute to the development of hypercalcemia. Vitamin D-mediated hypercalcemia was also reported as another common etiology for the condition. It might occur secondary to overdosing, immobilization, endocrine disorders, and granulomatous diseases. Other familial and congenital causes were also reported in the literature and discussed.

Funding: No funding sources

Conflict of interest: None declared

Ethical approval: Not required

\section{REFERENCES}

1. Bollerslev J, Pretorius M, Heck A. Parathyroid hormone independent hypercalcemia in adults. Best Practice Res Clin Endocrinol Metabol. 2018;32(5):621-38.

2. Huang J, Coman D, McTaggart SJ, Burke JR. Longterm follow-up of patients with idiopathic infantile hypercalcaemia. Pediatr Nephrol. 2006;21(11):167680.

3. Tinawi M. Disorders of Calcium Metabolism: Hypocalcemia and Hypercalcemia. Cureus. 2021;13(1):e12420.

4. Stokes VJ, Nielsen MF, Hannan FM, Thakker RV. Hypercalcemic Disorders in Children. J Bone Mineral Res. 2017;32(11):2157-70.

5. Giri D, McKay V, Weber A, Blair JC. Multiple endocrine neoplasia syndromes 1 and 2: manifestations and management in childhood and adolescence. Arch Dis Child. 2015;100(10):994-9. 
6. Goudet P, Dalac A, Le Bras M. MEN1 disease occurring before 21 years old: a 160-patient cohort study from the Groupe d'étude des Tumeurs Endocrines. J Clin Endocrinol Metabol. 2015;100(4):1568-77.

7. Newey PJ, Bowl MR, Cranston T, Thakker RV. Cell division cycle protein 73 homolog (CDC73) mutations in the hyperparathyroidism-jaw tumor syndrome (HPT-JT) and parathyroid tumors. Human Mutation. 2010;31(3):295-307.

8. Attie MF, Gill JR, Jr., Stock JL. Urinary calcium excretion in familial hypocalciuric hypercalcemia. Persistence of relative hypocalciuria after induction of hypoparathyroidism. J Clin Investigation. 1983;72(2):667-76.

9. Hannan FM, Nesbit MA, Christie PT. Familial isolated primary hyperparathyroidism caused by mutations of the MEN1 gene. Nature Clin Practice Endocrinol Metabol. 2008;4(1):53-8.

10. Wilhelm-Bals A, Parvex P, Magdelaine C, Girardin E. Successful use of bisphosphonate and calcimimetic in neonatal severe primary hyperparathyroidism. Pediatrics. 2012;129(3):e8126.

11. Pollak MR, Brown EM, Chou YH. Mutations in the human $\mathrm{Ca}(2+)$-sensing receptor gene cause familial hypocalciuric hypercalcemia and neonatal severe hyperparathyroidism. Cell. 1993;75(7):1297-303.

12. Nimesh $M$, Singh $P$, Jhamb U, Dubey AP. An Unsuspected Pharmacological Vitamin D Toxicity in a Child and its Brief Review of Literature. Toxicol Int. 2015;22(1):167-9.

13. Pérez-Barrios C, Hernández-Álvarez E, BlancoNavarro I, Pérez-Sacristán B, Granado-Lorencio F. Prevalence of hypercalcemia related to hypervitaminosis D in clinical practice. Clin Nutr. 2016;35(6):1354-8.

14. Wani M, Wani I, Banday K, Ashraf M. The other side of vitamin $\mathrm{D}$ therapy: a case series of acute kidney injury due to malpractice-related vitamin D intoxication. Clin Nephrol. 2016;86 (2016)(11):23641.

15. Gorris MA, Arora H, Lieb DC, Aloi JA. A Word of Caution When Prescribing High-Dose Vitamin D. Am J Med. 2017;130(4):e129-30.

16. Harnot J, Verma S, Singhi S, Sankhyan N, Sachdeva N, Bharti B. Comparison of 300,000 and 600,000 IU Oral Vitamin-D Bolus for Vitamin-D Deficiency in Young Children. Indian J Pediatr. 2017;84(2):111-6.

17. Emel T, Doğan DA, Erdem G, Faruk O. Therapy strategies in vitamin $\mathrm{D}$ deficiency with or without rickets: efficiency of low-dose stoss therapy. J pediatr Endocrinol Metabol. 2012;25(1-2):107-10.

18. Shepherd D, Belessis Y, Katz T, Morton J, Field P, Jaffe A. Single high-dose oral vitamin D3 (stoss) therapy--a solution to vitamin $\mathrm{D}$ deficiency in children with cystic fibrosis? J Cystic Fibrosis. 2013;12(2):177-82.
19. Viswanathan A, Quintos J. Stosstherapy for treatment of vitamin D deficiency rickets. Hospital Physician. 2006:39-42.

20. Dinour D, Beckerman P, Ganon L, Tordjman K, Eisenstein Z, Holtzman EJ. Loss-of-function mutations of CYP24A1, the vitamin D 24hydroxylase gene, cause long-standing hypercalciuric nephrolithiasis and nephrocalcinosis. J Urol. 2013;190(2):552-7.

21. Bosch X. Hypercalcemia due to endogenous overproduction of active vitamin D in identical twins with cat-scratch disease. JAMA. 1998;279(7):532-4.

22. Dinour D, Davidovits M, Aviner S. Maternal and infantile hypercalcemia caused by vitamin-Dhydroxylase mutations and vitamin D intake. Pediatr nephrol. 2015;30(1):145-52.

23. Levendoglu-Tugal O, Kroop S, Rozenblit GN, Weiss R. Primary renal lymphoma and hypercalcemia in a child. Leukemia lymphoma. 2002;43(5):1141-6.

24. Seymour JF, Gagel RF. Calcitriol: the major humoral mediator of hypercalcemia in Hodgkin's disease and non-Hodgkin's lymphomas. Blood. 1993;82(5):138394.

25. Demirkaya M, Sevinir B, Yalçinkaya U, Yazici Z. Disseminated rhabdomyosarcoma presenting as hypercalcemia. Indian pediatrics. 2012;49(1):66-7.

26. Nourani M, Manera RB. Pediatric ovarian dysgerminoma presenting with hypercalcemia and chronic constipation: a case report. J Pediatr Hematol/ Oncol. 2013;35(7):e272-3.

27. Grunewald TG, von Luettichau I, Welsch U, et al. First report of ectopic ACTH syndrome and PTHrPinduced hypercalcemia due to a hepatoblastoma in a child. Eur J Endocrinol. 2010;162(4):813-8.

28. Watanabe N, Yasuda H, Morishita S. Richter's Syndrome with Hypercalcemia Induced by TumorAssociated Production of Parathyroid HormoneRelated Peptide. Case Rep Oncol. 2017;10(1):123-6.

29. Lietman SA, Germain-Lee EL, Levine MA. Hypercalcemia in children and adolescents. Current Opinion Pediatr. 2010;22(4):508-15.

30. Srivastava T, Kats A, Martin TJ, Pompolo S, Alon US. Parathyroid-hormone-related protein-mediated hypercalcemia in benign congenital mesoblastic nephroma. Pediatric Nephrol. 2011;26(5):799-803.

31. Takeda K, Hara N, Kawaguchi M, Nishiyama T, Takahashi K. Parathyroid hormone-related peptideproducing non-familial pheochromocytoma in a child. Int J Urol. 2010;17(7):673-6.

32. Al Kalbani N, Frieling M, Teh JC, Harvey E, Geary DF. Idiopathic hypercalcemia in infants with renal dysplasia. Clin Nephrol. 2011;75(5):466-71.

33. Kimura S, Nishimura Y, Yamaguchi K, Nagasaki K, Shimada K, Uchida H. A case of pheochromocytoma producing parathyroid hormone-related protein and presenting with hypercalcemia. J Clin Endocrinol Metabol. 1990;70(6):1559-63.

34. Rosen JF, Wolin DA, Finberg L. Immobilization hypercalcemia after single limb fractures in children 
and adolescents. Am J Dis Children. 1978;132(6):560-4.

35. Maynard FM, Imai K. Immobilization hypercalcemia in spinal cord injury. Arch Physical Med Rehabilitation. 1977;58(1):16-24.

36. Faqeih E, Al-Akash SI, Sakati N, Teebi PA. Four siblings with distal renal tubular acidosis and nephrocalcinosis, neurobehavioral impairment, short stature, and distinctive facial appearance: a possible new autosomal recessive syndrome. Am J Med Genetics Part A. 2007;143a(17):1951-7.

37. Scheinman SJ, Guay-Woodford LM, Thakker RV, Warnock DG. Genetic disorders of renal electrolyte transport. N Eng J Med. 1999;340(15):1177-87.

38. Son PT, Reda A, Viet DC. Exchange transfusion in the management of critical pertussis in young infants: a case series. Vox sanguinis. 2021;116(9):976-82.

39. Gross I, Siedner-Weintraub Y, Simckes A, Gillis D. Antenatal Bartter syndrome presenting as hyperparathyroidism with hypercalcemia and hypercalciuria: a case report and review. J Pediatr Endocrinol Metabol. 2015;28(7-8):943-6.

40. Cervera A, Corral MJ, Gómez Campdera FJ, De Lecea AM, Luque A, López Gómez JM. Idiopathic hypercalciuria in children. Classification, clinical manifestations and outcome. Acta paediatrica Scandinavica. 1987;76(2):271-8.

41. Marabelle A, Sapin V, Rousseau R, Periquet B, Demeocq F, Kanold J. Hypercalcemia and 13-cisretinoic acid in post-consolidation therapy of neuroblastoma. Pediatric Blood Cancer. 2009;52(2):280-3.

42. Safi KH, Filbrun AG, Nasr SZ. Hypervitaminosis A causing hypercalcemia in cystic fibrosis. Case report and focused review. Ann Am Thoracic Society. 2014;11(8):1244-7.
43. Nguyen TM, Huan VT, Reda A. Clinical features and outcomes of neonatal dengue at the Children's Hospital 1, Ho Chi Minh, Vietnam. J Clin Virol. 2021;138:104758.

44. Vasikaran SD, Tallis GA, Braund WJ. Secondary hypoadrenalism presenting with hypercalcaemia. Clinical endocrinology. 1994;41(2):261-4.

45. Eriksen EF, Mosekilde L, Melsen F. Trabecular bone remodeling and bone balance in hyperthyroidism. Bone. 1985;6(6):421-8.

46. Laufer J, Noff D, Orda S, Sack J. Effect of short-term hyperthyroxinemia on vitamin $\mathrm{D}$ metabolism in congenital hypothyroidism. Hormone metabolic res. 1993;25(7):386-8.

47. Tau C, Garabedian M, Farriaux JP, Czernichow P, Pomarede R, Balsan S. Hypercalcemia in infants with congenital hypothyroidism and its relation to vitamin $\mathrm{D}$ and thyroid hormones. $\mathrm{J}$ pediatr. 1986;109(5):808-14.

48. Pober BR. Williams-Beuren syndrome. N Eng J Med. 2010;362(3):239-52.

49. Schipani E, Langman C, Hunzelman J. A novel parathyroid hormone (PTH)/PTH-related peptide receptor mutation in Jansen's metaphyseal chondrodysplasia. J Clin Endocrinol Metabol. 1999;84(9):3052-7.

50. Tran HA, Song S, Crock PA, Mattes J, Howard K. The A, B, C, D of hypercalcaemia in Down syndrome. BMJ case reports. 2009;2009.

Cite this article as: Rahman RS, Al-Saffar HF, Alasiri OA, Alata NJ, Almalki AA, Althenayan MAJ et al. Dependent and independent causes of hypercalcemia. Int J Community Med Public Health 2022;9:958-63. 